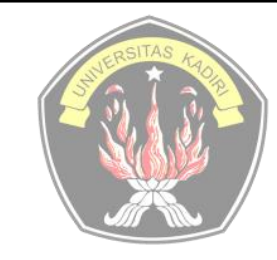

Tersedia online di

http://ojs.unik-kediri.ac.id/index.php/ekonika

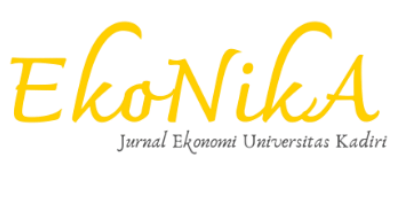

\title{
Pengaruh Ekonomi Global Dan Domestik Terhadap Inflasi Di Indonesia
}

\author{
Dini Hariyanti ${ }^{1}$, Soeharjoto ${ }^{2}$ \\ 1,2, Universitas Trisakti \\ email: ${ }^{1}$ dinihariyanti88@gmail.com, ${ }^{2}$ soeharjoto@trisakti.ac.id
}

\section{Artikel History:}

Artikel masuk : 06-10-2019

Artikel revisi : 01-12-2019

Artikel diterima : 18-03-2020

\section{Keywords:}

inflasi, kurs, harga minyak, JUB, suku bunga, PDB.

\begin{tabular}{l}
\hline ABSTRAK \\
\hline Inflasi merupakan salah satu penghambat terbesar dalam \\
kemajukan perekonomian suatu negara. Untuk itu, pemerintah \\
mengupayakan agar negaranya memiliki inflasi yang rendah dan \\
stabil. Penelitian ini bertujuan untuk mengetahui pengaruh \\
ekonomi global dan domestik terhadap inflasi di Indonesia, dengan \\
menggunakan data time series, berupa kuartalan pada 2009-2018, \\
yang berasal dari Statistik Ekonomi dan Keuangan Indonesia \\
(SEKI), International Financial Statistics (IFS), dan Investing. \\
Metode yang digunakan regresi dengan model ECM. Adapun hasil \\
yang diperoleh untuk jangka pendek, tingkat suku bunga dan kurs \\
berpengaruh positif signifikan dengan inflasi, tetapi JUB, PDB, \\
harga minyak tidak signifikan, sedangkan dalam jangka panjang, \\
tingkat suku bunga dan harga minyak berpengaruh positif \\
signifikan dengan inflasi, sedangkan JUB, PDB, Kurs tidak \\
signifikan. Adapun kebijakan yang dilakukan pemerintah, dengan \\
mengawasi dan mengantisipasi adanya gejolak ekonomi global dan \\
domestik, yakni menjaga kestabilan tingkat suku bunga dan kurs, \\
serta menggunakan sumber daya alternatif yang ramah lingkungan, \\
agar dapat mengurangi ketergantungan terhadap minyak. \\
Dismaping itu, Pemerintah perlu mengupayakan peningkatan PDB \\
untuk menjaga daya beli masyarakat dan penyaluran JUB \\
diarahkan untuk bidang yang produktif dan memiliki nilai tambah \\
yang besar, dengan memanfaatkan sumber daya lokal. \\
\hline
\end{tabular}
ABSTRACT

One of the biggest obstacles for countries economic growth compound is inflation. Government attempted to have lower and stable inflation. Purpose of this research is to determine effect of the global and domestic economy to inflation in Indonesia. Using quarterly time series data from 2009-2018 derived from the Indonesian Economic and Financial Statistics (SEKI), International Financial Statistics (IFS), and Investing. ECM regression model used for this research. For short term, interest rate and exchange rates have positive and significant effect to inflation. But money supply, GDP and oil price not significant, while in long term, interest rate and oil price have positive and significant to inflation, while money supply, GDP and exchange rates are not significant. Government policies are monitoring and anticipating global and domestic fluctuation, by maintaining the stability of interest rate and exchange rates, and also using environmentally friendly alternatives resources, in order to 
reducing dependence on oil. Besides that, government needs to undertake increasing of GDP to maintain people purchasing power and money supply distribution for productive sector which have biggest adding value by utilizing local resources.

\section{PENDAHULUAN}

Kemajuan teknologi digital yang pesat, membuat semakin besarnya keterkaitan dan ketergantungan perekonomian antar negara di dunia, sehingga membuat negara tanpa batas (Tribudhi dan Soekapdjo, 2019). Hal ini, dapat terjadi dengan adanya gejolak perekonomian di negara maju, yang akan segera berdampak pada negara lainnya (Soekapdjo dkk, 2019). Untuk itu, negara dalam menjaga kestabilan ekonomi, dengan membuat kebijakan ekonomi domestik, yang juga memperhatikan serta dapat mengantisipasi dari adanya gejolak ekonomi global.

Pertumbuhan ekonomi yang stabil dan diikuti dengan tren positif, menunjukkan kondisi ekonomi makro yang ideal. Inflasi merupakan indikator untuk stabilitas ekonomi negara. Hal ini, terjadi karena adanya inflasi pada akhirnya akan berdampak pada sektor ekonomi makro lainnya. Padahal, inflasi dapat terjadi diluar ekspektasi. Inflasi merupakan fenomena alami dalam perekonomian dan tidak menjadi masalah, selama inflasinya rendah dan stabil, sehingga mudah dikendalikan. Namun, apabila inflasi yang terjadi tinggi dan tidak stabil akan sulit untuk dapat dikendalikan, yang dapat berakibat fatal, yakni krisis ekonomi. Indonesia pernah mengalami inflasi yang tinggi dan berdampak pada krisis ekonomi, yakni pada era orde lama dan 1998. Apabila inflasi yang terlalu rendah, justru akan memberikan dampak lesunya perekonomian, karena dengan harga rendah tidak memberikan stimulan pada sektor riil, sehingga mereka tidak mau melakukan kegiatan produksi. Hal ini, terjadi karena dengan harga rendah tidak akan dapat menutupi biaya produksinya. Untuk itu, perlu dijaga inflasi yang rendah dan stabil, agar aktivitas ekonomi dapat berjalan dengan baik.

Untuk kawasan ASEAN, Indonesia memiliki inflasi tinggi dan termasuk dalam tiga besar. Inflasi yang terjadi di negara anggota ASEAN, pada 2009-2018 dengan rerata 3,16 persen, yang meliputi Vietnam sebesar 6,62 persen, Myanmar sebesar 5,41 persen, Indonesia sebesar 4.89 persen, Laos sebesar 3,42 persen, Filipina sebesar 3,19 persen, Kamboja sebesar 2,81 persen, Malaysia sebesar 2,12 persen, Singapura sebesar 1,66 persen, Thailand sebesar 1,43 persen, dan Brunei Darussalam sebesar 0,07 persen. Padahal, Indonesia merupakan negara pendiri ASEAN pada 8 Agustus 1967, sedangkan kedua negara lainnya baru bergabung, yakni Vietnam pada 28 Juli 1995 dan Myanmar di 23 Juli 1997. Kondisi ini dapat terjadi, karena Indonesia merupakan negara yang memiliki wilayah luas dan berbentuk kepulauan, jumlah penduduk banyak dengan beragam suku dan agama, sehingga keadaannya lebih kompleks. Namun demikian, 
perekonomiannya cukup kondusif karena memiliki sumber daya alam dan manusia yang berlimpah, yang tercermin dari pertumbuhan ekonomi yang dicapainya. Kesejahteraan masyarakat Indonesia, sebenarnya dapat lebih optimal lagi, apabila pemerintah dapat menekan inflasi, yang berdampak pada peningkatan daya beli masyarakat.

\section{Gambar 1. Inflasi di Negara Anggota ASEAN, Pada 2009-2018 (Persen).}

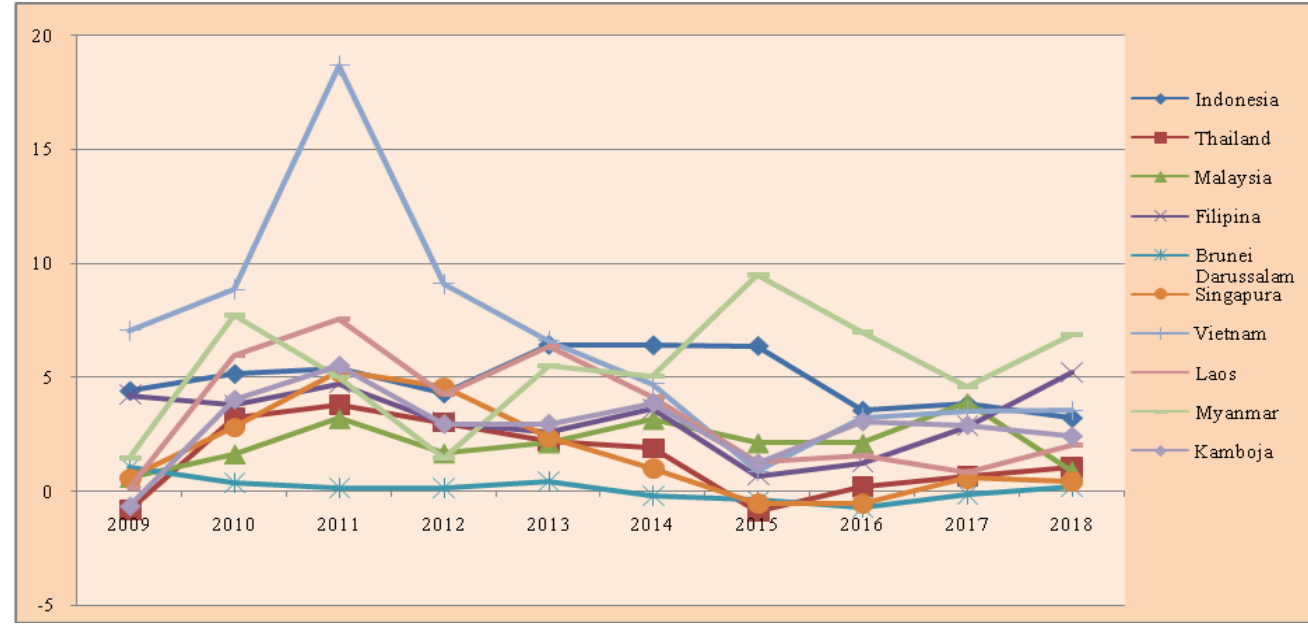

Sumber: www.worldbank.org

Adanya gejolak ekonomi global, akan mengganggu kestabilan perekonomian nasional, terutama yang berkaitan dengan perubahan harga minyak dan kurs yang tidak terkendali. Harga minyak dunia terus mengalami fluktuatif, dengan kecenderungan tren meningkat, karena minyak masih merupakan sumber utama dalam proses produksi, sehingga berdampak pada faktor fundamental, berupa aksioma yang berlaku di pasar, dan non fundamental, yakni terkait dengan infrastruktur, geopolitik, dan spekulasi (Bhar dan Malliaris, 2011). Pada saat ini, perekonomian di Indonesia menjadi semakin terintegrasi dengan sistem keuangan global, karena nilai kurs rupiah juga mendapatkan dampak langsung dari gejolak ekonomi global (Nurhasanah dan Soekapdjo, 2019). Kestabilan ekonomi domestik, juga merupakan dampak dari kebijakan yang diambil pemerintah, guna mensejahterakan masyarakat. Namun demikian, dalam membuat kebijakan perlu berhati-hati, karena terdapat beberapa kebijakan yang cukup sensitif, yang berdampak inflasi. Hal ini, dapat terjadi karena adanya kontradiksi dari kebijakan yang diambil, yang berkaitan dengan jumlah uang beredar (JUB), tingkat suku bunga, dan Produk Domestik Bruto (PDB). Walaupun demikian, Pemerintah perlu tetap menjaga agar perekonomian dalam kondisi yang kondusif.

Perekonomian negara akan terganggu dengan adanya fluktuatif inflasi yang ekstrim. Agar perekonomian dapat berkembang dengan baik, diperlukan inflasi yang rendah dan stabil. Inflasi dapat terjadi karena faktor domestik dan ekonomi global. Harga minyak dunia serta kurs merupakan proxy dari ekonomi global, dan PDB, BI rate, JUB merupakan proxy dari faktor 
domestik. Untuk itu, perlu dilakukan penelitian pengaruh faktor ekonomi global dan domestik terhadap inflasi di Indonesia. Dengan mengetahui faktor tersebut, pemerintah dapat dengan segera mengatasi massalah dengan membuat kebijakan yang tepat.

\section{TINJAUAN PUSTAKA}

Inflasi yang terjadi di Indonesia, memiliki latar belakang yang unik. Faktor yang mempengaruhi inflasinya, bukan hanya terjadi karena fenomena jangka pendek, akan tetapi juga merupakan fenomena jangka panjang (Baasir, 2003). Namun, inflasi yang terjadi merupakan The Triangle Model, yakni disebabkan permintaan (Philips curve inflation), penawaran (supply shocks inflation), dan ekspektasi (structural inflation) (Gordon, 1979). Dengan demikian, inflasi di Indonesia terjadi tidak hanya sesuai dengan teori kuantitas dan Keynes, tetapi juga sesuai dengan teori Neo-Keynesian.

Hingga kini, minyak merupakan sumber energi utama di dunia. Adanya peran besar dari minyak, berdampak pada tingginya permintaan. Padahal, minyak merupakan sumberdaya yang tidak dapat diperbaharui, sehingga pasokannya semakin lama semakin berkurang dan negara penghasil minyak juga semakin terbatas. Hal ini, akan semakin mengkondisikan semakin mudah terjadinya gejolak harga minyak dunia. Dampak dari oil shocks pada 1970, menjadi perhatian dunia hingga kini, karena berdampak pada resesi ekonomi di Amerika dan Eropa (Hamilton, 1996). Kondisi ini, akan berdampak pada semakin tinggi inflasi dan diikuti pertumbuhan ekonomi yang negatif. Adanya oil price shock dunia, akan berakibat perusahaan melakukan respon dengan melakukan mark up harga, karena terjadinya peningkatan biaya produksi, yang berujung pada inflasi. Peningkatan harga minyak, juga akan diikuti peningkatan harga produk lainnya, yang akhirnya berdampak pada inflasi (Cologni dan Manera, 2008). Disamping itu, adanya kenaikan harga produk, berakibat adanya tuntutan dari masyarakat untuk ditingkatkan upahnya, sehingga juga akan berdampak pada inflasi (Lurdic dan Mignon, 2008). Penelitian Bala dan Chin (2018), mengungkapkan bahwa inflasi berpengaruh signifikan positif terhadap inflasi.

Perekonomian negara akan kondusif, bila memiliki nilai kurs yang stabil. Nilai mata uang Indonesia, diwarnai dengan adanya gejolak volatilitas dan tekanan baik dari luar negeri maupun dalam negeri. Bahkan, dampak global memberikan peran yang besar terhadap kestabilan kursnya. Adapun dampak dari tekanan terhadap kurs dapat berakibat fatal, terutama terkait dengan akan terjadinya pelarian dana dan investasi asing dari dalam negeri ke negara lain, terutama disebabkan hilangnya kepercayaan dari masyarakat dan investor, yang akan berujung pada krisis ekonomi. Indonesia mengalami beberapa kali yang mengakibatkan ketidak stabilan 
kursnya yang berakibat fatal, dan akhirnya pada 14 Agustus 1997, menetapkan kebijakan nilai tukar dari managed floating exchange rate menjadi flexible exchange rate. Walupun demikian, adanya tekanan kuat dari ekonomi global masih juga tetap dapat membuat gejolak terhadap kursnya. Namun, gejolak yang dialami tidak seekstrim pada sistem yang digunakan sebelumnya. Perilaku dari fluktuatif kurs akan mengganggu stabilitas makro ekonomi nasional terutama pertumbuhan dan inflasi. Hasil penelitian Monfared dan Akin (2017), mengungkapkan bahwa ada pengaruh yang positif signifikan antara kurs dengan inflasi.

Keberhasilan pembangunan ekonomi negara, tercermin dari Produk domestik bruto (PDB). Adanya peningkatan PDB, biasanya diikuti dengan peningkatan inflasi. PDB yang tinggi, akan memberikan dampak pada peningkatan pendapatan masyarakat, dan diikuti dengan peningkatan pengeluaran, bahkan akan terjadi pengeluaran diluar batas kemampuannya, yang akan berdampak pada inflasi. PDB yang semaikin tinggi, juga akan mengakibatkan terjadinya haigh cost economy, yang berujung pada inflasi. Penelitian Daniela (2015), menunjukkan bahwa terdapat pengaruh yang positif dan signifikan PDB dengan inflasi.

Jumlah uang beredar (JUB), memberikan peran yang besar juga terhadap inflasi. Kondisi ini terjadi, karena adanya peningkatan JUB, akan memberikan dampak pada peningkatan roda perekonomian, yang akhirnya akan meningkatkan pendapatan masyarakat, sehingga mereka akan meningkatkan pengeluarannya, yang berdampak pada peningkatan permintaan yang berujung pada inflasi (Langi dkk, 2014). Ofori dkk (2017), menemukan bahwa jumlah uang beredar berpengaruh positif signifikan terhadap inflasi.

Kebijakan moneter yang ekspansif dan kontraktif dapat dilakukan melalui BI rate. Pada saat perekonomian lesu, guna meningkatkan aktivitas ekonomi dapat dilakukan kebijakan ekspansif, melalui penurunan suku bunga, yang akan meningkatkan pinjaman, guna menambah modal usaha. Hal ini, akan berdampak pada peningkatan ekonomi, yang berakibat bertambahnya pendapatan dan permintaan masyarakat, yang berujung pada inflasi. Untuk mengatasi hal ini, biasanya Bank Indonesia akan melakukan kebijakan kontraktif dengan meningkatkkan BI rate (www.bi.go.id). Penelitian Kalalo dkk (2016), mengungkapkan bahwa BI rate berpengaruh positif signifikan terhadap inflasi.

\section{METODE PENELITIAN}

Penelitian ini menggunakan regresi dengan model Error Correction Model (ECM), untuk melihat pengaruh jangka pendek dan jangka panjang. Data yang digunakan time series, dengan periode waktu kuartalan pada 2009.1-2018.4. Data bersumber dari Statistik Ekonomi dan Keuangan Indonesia (SEKI), International Financial Statistics (IFS), Investing. Penggunaan 
asumsi klasik (normalitas, multikolinearitas, heterokedastisitas, autokorelasi), uji Statistik yang meliputi koefisien determinasi (R-square), uji global (uji F), uji individu ( uji t). Adapun model dalam penelitian ini adalah:

$$
\text { Inflasi }_{\mathrm{t}}=\beta \mathrm{o}+\beta_{1} \mathrm{JUB}_{\mathrm{t}}+\beta_{2} \text { Skbungat }_{\mathrm{t}}+\beta_{3} \mathrm{PDB}_{\mathrm{t}}+\beta_{4} \mathrm{Kurs}_{\mathrm{t}}+\beta_{5} \text { Pminyak }_{\mathrm{t}}+\varepsilon_{\mathrm{t}}
$$

Keterangan:

$$
\begin{array}{ll}
\text { Inflasi } & =\text { Inflasi dari IHK (Persen). } \\
\text { JUB } & =\text { Jumlah Uang Beredar (Rp. Trilyun). } \\
\text { Skbunga } & =\text { Suku bunga BI rate (Persen). } \\
\text { PDB } & =\text { Produk Domestik Bruto Harga konstan } 2010 \text { (Rp. Trilyun). } \\
\text { Kurs } & =\text { Nilai tukar rupiah terhadap dollar Amerika (Rp. per USD). } \\
\text { Pminyak } & =\text { Harga minyak mentah dunia (USD per barel). }
\end{array}
$$

\section{HASIL \& PEMBAHASAN}

Rerata inflasi kuartalan di Indonesia pada 2009.1-2018.4 cukup tinggi sebesar 4,931 persen, dengan standar deviasi sebesar 2,780 persen, sehingga memiliki variasi antar kuartal cukup signifikan dan memiliki tren yang fluktuatif di 2009-2015, namun semenjak 2016 trennya mengalami menurun dan relatif stabil. JUB memiliki tren meningkat, namun memiliki variasi yang besar berstandar deviasi Rp 1135,6 trilyun, dengan nilai tertinggi Rp. 5.284,3 triliun dan terendah Rp. 1.594,3 triliun, yang reratanya pada 2009.1-2018.4 sebesar Rp 3.277,8 trilyun. Suku bunga di Indonesia pada 2009.1-2018.4 dengan rerata 6,293 persen, yang memiliki tren berfluktuatif, berstandar deviasi 1,042 persen, yang menunjukkan adanya variasi cukup besar antara suku bunga satu kuartal dengana kuartal lainnya, dengan suku bunga terendah 4,25 persen dan tertinggi 7,75 persen. PDB di Indonesia memiliki tren yang meningkat pada 2009.1-2018.4, dengan rerata Rp 2.092,9 trilyun, yang memiliki variasi cukup besar dengan standar deviasi Rp 324,4 trilyun, yang memiliki nilai terendah Rp. 1548,9 trilyun tertinggi Rp. 2683,2 trilyun. Harga minyak pada 2009-2014 tinggi, kemudian setelah 2015 turun dan relatif stabil, dengan rerata harga pada 2009-2018 sebesar 73,56 USD per barel, dengan standar deviasi sebesar 21,95 USD per barel, yang berarti variasi harga minyak dunia yang cukup besar antara satu kuartal dengan kuartal lainnya, dengan harga tertinggi 106,72 USD per barel dan terendah 37,04 USD per barel. Kurs mengalami tren menguat pada 2009-2011, setelah itu terus mengalami tren penurunan, yang pada 2009-2018 memiliki terata sebesar Rp 11.514,8 per USD, dengan standar deviasi 2083,7, yang berarti variasi cukup besar 
antara satu kuartal dengan kuartal lainnya, yang nilai tertingginya Rp. 8.597 per USD dan terndahnya Rp. 14.929 per USD.

Tabel 1. Statistik Deskriptif Variabel Penelitian

\begin{tabular}{lrrrrrr}
\hline & \multicolumn{7}{c}{ SKBUNG } \\
\multicolumn{1}{c}{ Variabel } & INFLASI & \multicolumn{1}{c}{ JUB } & \multicolumn{1}{c}{ A } & GDP & KURS & PMINYAK \\
\hline Mean & 4.931 & 3277.8 & 6.293 & 2092.9 & 11514.8 & 73.566 \\
Maximum & 8.400 & 5284.3 & 7.750 & 2683.2 & 14929.0 & 106.72 \\
Minimum & 2.780 & 1594.3 & 4.250 & 1548.9 & 8597.0 & 37.04 \\
Std. Dev. & 1.764 & 1135.6 & 1.042 & 324.4 & 2083.7 & 21.95 \\
Jarque-Bera & 3.903 & 3.042 & 2.245 & 2.021 & 4.001 & 3.365 \\
Probability & 0.142 & 0.218 & 0.325 & 0.363 & 0.135 & 0.185 \\
Observations & 40 & 40 & 40 & 40 & 40 & 40 \\
\hline
\end{tabular}

Sumber : data diolah

Dilakukan Pengujian akar-akar unit bertujuan untuk menguji apakah setiap variabel yang digunakan pada penelitian ini stationer pada level. Adapun hasilnya, tingkat level terdapat 1 variabel yang stasioner yaitu inflasi, tetapi ke lima variabel lainnya yaitu JUB, suku bunga, PDB, Kurs dan harga minyak tidak stasioner, karena menghasilkan nilai prob dari PP test>0,05. Padahal, bila tidak seluruh variabel stasioner pada tingkat level, maka perlu dilakukan pengujian derajat integrasi (fist difference).

Tabel 2. Uji Akar-Akar Unit

\begin{tabular}{lccc}
\hline \multicolumn{1}{r}{ Variabel } & PP test & Prob. & Keterangan \\
\hline Inflasi & -3.245 & 0.024 & Stasioner \\
JUB & 1.966 & 0.999 & Tidak stasioner \\
Suku Bunga & -2.026 & 0.274 & Tidak stasioner \\
PDB & -0.161 & 0.935 & Tidak stasioner \\
Kurs & -0.315 & 0.913 & Tidak stasioner \\
Harga Minyak & -1.774 & 0.387 & Tidak stasioner \\
\hline
\end{tabular}

Sumber: data diolah

Hasil pengujian derajat integrasi, menunjukkan keseluruhan variabel yang digunakan dalam penelitian stasioner pada derajat 1, yang ditunjukkan dengan nilai prob. dari PP test $<0,05$. Dikarenakan keseluruhan variabel stasioner pada derajat 1 (first difference), maka model yang cocok digunakan dalam mengestimasi pengaruh variabel independen terhadap variabel dependen adalah Model Koreksi Kesalahan (Error Correction Model).

Tabel 3. Uji Akar-Akar Unit

\begin{tabular}{lllc}
\hline \multicolumn{1}{c}{ Variabel } & PP test & Prob. & Kesimpulan \\
\hline Inflasi & -8.001 & 0.000 & Stasioner \\
JUB & -5.839 & 0.000 & Stasioner \\
Suku Bunga & -4.419 & 0.001 & Stasioner \\
PDB & -8.517 & 0.000 & Stasioner \\
Kurs & -5.773 & 0.000 & Stasioner \\
Harga Minyak & -5.115 & 0.000 & Stasioner \\
\hline Sumber: data diolah & & &
\end{tabular}


Uji kointegrasi terhadap variabel-variabel, dilakukan untuk mengetahui hubungan jangka panjang dari model tersebut. Hasil pengolahan menunjuukkan nilai prob dari koefisien ECT sebesar $0,0017<0,05$, sehingga terjadi kointegrasi pada model inflasi yang artinya dalam jangka panjang.

\section{Tabel 4. Uji Kointegrasi}

\begin{tabular}{|c|c|c|c|}
\hline Variabel & PP test & Prob. & Kesimpulan \\
\hline ECT & -4.263075 & 0.0017 & Berkointegrasi \\
\hline
\end{tabular}

Sumber: data diolah

Sebelum dilakukan pengujian hipotesis teori, terlebih dahulu dilakukan pengujian asumsi klasik, pada model jangka pendek. Hasil pengujian normalitas, menghasilkan nilai prob dari jarque berra sebesar $0,678>0,05$, yang artinya distribusi dari residual normal. Pengujian multikolinearitas diperoleh nilai $\mathrm{VIF}<10$, sehingga dapat disimpukan tidak terdapat multikolinearitas. Pengujian autokorelasi dengan menggunakan LM test, yang menghasilkan nilai prob dari LM test sebesar 0,644>0,05, yang artinya model yang dihasilkan terbebas dari masalah autokorelasi. Uji heteroskedastisitas dengan menggunakan pengujian white test, yang menghasilkan nilai prob dari White test sebesar $0,986>0,05$, yang artinya model yang dihasilkan tidak terdapat heteroskedastisitas.

Tabel 5. Hasil Estimasi Model Inflasi Jangka Pendek

\begin{tabular}{lcccc}
\hline \multicolumn{1}{c}{ Variabel } & \multicolumn{3}{c}{ Kariabel Dependen : Inflasi } & \\
\hline C & 0.688 & 1.563 & 0.127 & 0.19386 \\
JUB & -0.008 & -2.023 & $0.026^{*}$ & $1.77 \mathrm{E}-05$ \\
SKBUNGA & 0.503 & 1.050 & $0.150^{* *}$ & 0.229487 \\
PDB & -0.002 & -0.608 & $0.273^{*}$ & $1.30 \mathrm{E}-05$ \\
KURS & 0.001 & 2.990 & $0.002^{*}$ & $1.70 \mathrm{E}-07$ \\
PMINYAK & 0.001 & 0.073 & $0.475^{*}$ & 0.000264 \\
ECT & -0.572 & -3.713 & 0.000 & \\
\hline R $^{2}$ Adjusted & 0.401 & Jarque Berra & 0,776 & \\
F statistic & 5,248 & Prob & 0,678 & \\
Prob & 0,000 & White & 13.35 & \\
LM test & 0,212 & Prob & 0.986 & \\
Prob & 0,644 & & & \\
\hline
\end{tabular}

Keterangan:

$$
\begin{aligned}
& *=\text { Alfa } 5 \text { persen } \\
& * *=\text { Alfa } 10 \text { persen }
\end{aligned}
$$

Sumber: data diolah 
Pengujian hipotesis teori terdiri atas tiga macam, yakni goodness of fit, global, dan individu (uji t). Pengujian model fit ditunjukkan dengan nilai $\mathrm{R}^{2}$ adjusted sebesar 0,401 , yang artinya bahwa variasi atau perilaku dari variabel independen mampu menjelaskan variasi dari perilaku variabel dependen sebesar 40,1 persen, sedangkan sisanya yang 59,9 persen merupakan variasi dari variabel independen lain yang mempengaruhi inflasi tetapi tidak dimasukkan dalam model. Pengujian global (uji F) memiliki nilai prob dari F sebeasr $0,000<0,05$, yang artinya terbukti paling sedikit terdapat 1 variabel independen yang berpengaruh signifikan terhadap inflasi. Pengujian individu diperoleh:

1. Dari hasil perhitungan diperoleh nilai koefisien estimasi sebesar minus 0,008 dan Prob. $0,026 / 2=0,013<0,05$ namun arahnya terbalik, yang artinya JUB berpengaruh negatif terhadap inflasi, dimana meningkatnya JUB akan menurunkan inflasi dan sebaliknya. Hasil temuan ini menunjukkan bahwa hipotesis teori yang menyatakan bahwa JUB berpengaruh positif terhadap inflasi dalam jangka pendek tidak terbukti.

2. Hasil pengolahan ditunjukkan dengan nilai koefisien sebesar 0,503 , yang artinya meningkatnya suku bunga akan meningkatkan inflasi dan sebaiknya, menurunnya suku bunga akan menurunkan inflasi. Dengan nilai t statistik sebesar 1,050 diperoleh nilai prob sebesar $0,150 / 2=0,075<0,1$, yang artinya suku bunga terbukti berpengaruh positif signifikan terhadap inflasi.

3. Hasil perhitungan diperoleh nilai koefisien estimasi sebesar minus 0,002 dengan Prob $0,273 / 2=0,1365>0,05$, yang artinya meningkatnya PDB akan menurunkan inflasi dan sebaliknya, menurunnya PDB akan meningkatkan inflasi. Hasil temuan ini menunjukkan bahwa hipotesis teori yang menyatakan adanya pengaruh positif dari PDB terhadap inflasi tidak terbukti.

4. Hasil perhitungan ditunjukkan dengan nilai koefisien estimasi sebesar 0,001, yang artinya depresiasi rupiah terhadap dolar akan meningkatkan inflasi dan sebaliknya, apresiasi rupiah terhadap dolar akan menurunkan inflasi. Dengan nilai prob sebeasr $0,002 / 2=0,001<0,05$, yang artinya pengaruh depresasi rupiah terhadap dolar akan meningkatkan inflasi terbukti.

5. Hasil perhitungan diperoleh koefisien estimasi sebesar 0,001 , yang artinya meningkatnya harga minyak dunia akan meningkatkan inflasi dan sebaliknya, menurunnya harga minyak dunia akan menurunkan inflasi. Dengan prob sebesar $0,475 / 2=0,2375>0,05$, yang artinya pengaruh positif dari harga minyak dunia terhadap inflasi tidak signifikan.

Pengujian asumsi klasik untuk model ECM jangka panjang. Hasil pengujian normalitas, ditunjukkan dengan nilai jarque berra sebesar 0,153 , dengan prob sebesar $0,920>0,05$, yang artinya distribusi dari residual terbukti bersifat normal. Pengujian multikolinearitas 

tidak ada multikolinearitas antara variabel independen yang digunakan dalam model. Hasil pengujian autokorelasi dengan LM test, diperoleh nilai LM statistik sebear 1,565, dengan prob sebesar 0,210>0,05, yang artinya tidak terdapat autokorerlasi pada model yang dihasikan. Pengujian heteroskedastisitas dengan menggunakan pengujian white test menghasilkan nilai prob dari White test sebesar $0,178>0,05$, yang artinya model yang dihasilkan tidak terdapat heteroskedastisitas.

Tabel 6. Hasil Estimasi Model Inflasi Jangka Penjang

\begin{tabular}{lcccc}
\hline \multicolumn{5}{c}{ Variabel Dependen : Inflasi } \\
\hline Variabel & Koefisien & t statistik & Prob. & VIF \\
\hline C & -5.337 & -0.854 & 0.199 & 39.001 \\
SKB & $2.85 \mathrm{E}-05$ & 0.016 & $0.493^{*}$ & $2.96 \mathrm{E}-06$ \\
PDB & 0.764 & 2.180 & $0.018^{*}$ & 0.122761 \\
KURS & 0.002 & 0.598 & $0.276^{*}$ & $2.28 \mathrm{E}-05$ \\
PMINYAK & -0.0003 & -0.702 & $0.243^{*}$ & $2.12 \mathrm{E}-07$ \\
\hline $\mathrm{R}^{2}$ Adjusted & 0.0149 & 0.986 & $0.165^{* *}$ & 0.000229 \\
F statistik & 0.465 & Jarque Berra & 0,153 & \\
Prob & 6,520 & Prob & 0,920 & \\
LM test & 0,000 & White & 33.58 & \\
Prob & 1,565 & Prob & 0.178 & \\
\hline
\end{tabular}

Keterangan:

$*=$ Alfa 5 persen

$* *=$ Alfa 10 persen

Sumber: data diolah

Hasil pengolahan memiliki nilai $\mathrm{R}^{2}$ adjusted sebsar 0,465 , yang artinya variasi atau perilaku dari variabel independen mampu menjelaskan variasi dari perilaku variabel dependen sebeasr 46,5 persen, sedangkan sisanya yaitu 53,5 persen merupakan variasi dari variabel independen lain yang mempengaruhi inflasi tetapi tidak dimasukkan dalam model. Hasi pengujian global (uji F), memiliki nilai F statistik sebesar 6,520 dengan prob dari F sebesar $0,000<0,05$, yang artinya terbukti paling sedikit terdapat 1 variabel independen yang berpengaruh signifikan terhadap inflasi. Hasil pengolahan untuk pengujian individu dapat dijelaskan sebagai berikut:

1. Hasil perhitungan diperoleh nilai koefisien estimasi sebesar 2,83E-05, yang artinya JUB berpengaruh positif terhadap inflasi dimana meningkatnya JUB akan meningkatkan inflasi dan sebaliknya, menurunnya JUB akan menurunkan inflasi. Dengan nilai prob sebesar 
$0,493 / 2=0,2465>0,05$, yang artinya pengaruh positif dari JUB terhadap inflasi tidak signifikan dalam jangka panjang.

2. Hasil pengolahan ditunjukkan dengan nilai koefisien sebeasr 0,764 , yang artinya meningkatnya suku bunga akan meningkatkan inflasi dan sebaiknya, menurunnya suku bunga akan menurunkan inflasi. Dengan nilai prob sebesar $0,018 / 2=0,009<0,05$, yang artinya suku bunga terbukti berpengaruh positif signifikan terhadap inflasi.

3. Hasil perhitungan diperoleh nilai koefisien estimasi sebesar 0,002, yang artinya meningkatnya PDB akan meningkatkan inflsi dan sebaliknya, menurunnya PDB akan menurunkan inflasi. Dengan nilai prob sebesar $0,276 / 2=0,138>0,05$, yang artinya adanya pengaruh positif dari PDB terhadap inflasi tidak terbukti.

4. Hasil perhitungan ditunjukkan dengan nilai koefisien estiimasi sebesar minus 0,0003, yang artinya depresiasi rupiah terhadap dolar akan menurunkan inflasi dan sebaliknya apreaiasi rupiah terhadap dolar akan menaikkan inflasi. Dengan nilai prob sebeasr $0,243 / 2=0,1215>0,05$, yang artinya pengaruh kurs rupiah terhadap dolar terhadap inflasi tidak signifikan.

5. Hasil perhitungan diperoleh koefisien estimasi sebesar 0,0149 , yang artinya meningkatnya harga minyak dunia akan meningkatkan inflasi dan sebaliknya, menurunnya harga minyak dunia akan menurunkan inflasi. Dengan nilai prob sebesar $0,165 / 2=0,0825<0,1$, yang artinya pengaruh positif dari harga minyak dunia terhadap inflasi signifikan.

Inflasi yang terjadi di Indonesia, dapat berasal dari dampak ekonomi global dan domestik. Adapun dampaknya, dapat dalam jangka pendek dan jangka panjang dengan inflasi yang bersumber dari permintaan, penawaran, dan ekspektasi. Inflasi yang bersumber dari domestik, tingkat suku bunga memiliki peran yang besar, karena dapat mempengaruhi inflasi baik untuk jangka pendek dan jangka panjang. Untuk faktor luar negeri, peran kurs hanya berdampak pada jangka pendek, namun untuk jangka panjang justru yang lebih berperan harga minyak. Keadaan ini, sesuai dengan penelitian Nuryati (2006), yang mengungkapkan bahwa variasi nilai kurs dapat terjadi dalam jengka pendek dan panjang, yang dipengaruhi shocks dari mata uang itu sendiri, sehingga kurs sulit dikendalikan untuk jangka pendek, dengan demikian untuk jangka panjang dapat diatasi, sehingga tidak memperparah kondisi inflasi yang terjadi. Kondisi yang demikian, pemerintah perlu mengawasi dan mengantisipasi adanya gejolak ekonomi global dan domestik. Adapun kebijakan yang perlu diambil, dengan menjaga kestabilan tingkat suku bunga dan kurs, melaui optimalisasi peran lembaga keuangan dalam menjalankan fungsinya sebagai intermediary yang dapat mendorong sektor riil, tetapi pemerintah juga perlu mengambil kebijakan penggunaan sumber daya alternatif yang ramah lingkungan, agar dapat mengurangi 
ketergantungan terhadap minyak (Arafah, 2018). Pemerintah perlu mengupayakan peningkatan PDB, juga dengan pemberdayaan SDA dan SDM, guna menjaga daya beli masyarakat dan penyaluran JUB secara cepat dan akurat, yang diarahkan untuk bidang yang produktif dan memiliki nilai tambah yang besar, dengan memanfaatkan sumber daya lokal.

\section{SIMPULAN \& SARAN}

Penelitian pengaruh ekonomi global dan domestic terhadap inflasi di Indonesia, yang menggunakan metode regresi dengan model ECM, akan diperoleh hasil untuk jangka pendek dan panjang. Hasil analisis model jangka pendek, diperoleh tingkat suku bunga dan kurs berpengaruh positif signifikan dengan inflasi, tetapi JUB, PDB, harga minyak tidak signifikan. Hasil analisis model jangka panjang, diperoleh tingkat suku bunga dan harga minyak berpengaruh positif signifikan dengan inflasi, sedangkan JUB, PDB, Kurs tidak signifikan. Dengan demikian, inflasi yang terjadi di Indonesia mengikuti teori strukturalis, Keynes, dan Neo Keynesian. Untuk itu, perlu adanya upaya dari pemerintah, agar dapat mengawasi dan mengantisipasi perekonomian dari gejolak ekonomi global dan domestik, melalui kebijakan menjaga kestabilan tingkat suku bunga dan kurs, penggunaan sumber daya alternatif yang ramah lingkungan, meningkatkan PDB, JUB diarahkan untuk bidang yang produktif dan memiliki nilai tambah yang besar, dengan memanfaatkan sumber daya lokal.

\section{DAFTAR PUSTAKA}

Arafah, Willy., Lucky Nugroho, Rowlan Takaya, Soeharjoto Soekapdjo. (2018). Marketing Strategy for Renewable Energy Development In Indonesia Context Today. International Journal of Energy Economics and Policy. Vol 8(5). 181-186.

Bala, Umar and Lee Chin. (2018). Asymmetric Impact of Oil Price on Inflation: An Empirical Study of African OPEC Member Countries. Energies. Vol. 11(11). 1-21.

Bhar, Ramaprasad., A.G. Maliaris. (2011). Oil Prices and the impact of the financial crisis 2007-2009. Energy Economics 33. 1049-1054.

Baasir, F. 2003. Pembangunan dan Crisis. Jakarta: Pustaka Sinar Harapan.

Cologni, Alessandro and Matteo Manera. (2008). Oil prices, inflation and interest rates in a structural cointegrated VAR model for the G-7 countries. Energy Economics. Vol. 3 0(3). 856-888.

Daniela, Sacalâ Christina. (2015). Analyzing the Impact of Gross Domestic Product Growth Rate on Inflation: Short Empirical Study for the Romanian Economy. International Journal of Economies and Management Sciences. Vol. 4(2).

Gordon, Robert J., (1997). The Time-Varying NAIRU and Its Implications for Economic Policy. Journal of Economic Perspectives. Vol. 11 (1). 11-32.

Hamilton, J.D. (1996). This is What Happened to Oil Price-Macroeconomy Relationship. Journal of Monetary Economics. Vol. 38(2). 215-220.

Kalalo, Harjunata Y.T., Tri Oldy Rotinsulu, Mauna Th. B. Maramis. (2016). Analisis FaktorFaktor Yang Mewmpengaruhi Inflasi di Indonesia Periode 2000-2014. Jurnal Berkala Ilmiah. Vol. 16(1). 706-717. 
Langi, theodores Manuela., Vecky Masinambow, Hanly Siwu. (2014). Analisis Pengaruh Suku Bunga BI, Jumlah Uang Beredar dan Tingkat Kurs Terhadap Tingkat Inflasi di Indonesia. Jurnal Berkala Ilmiah Efisiensi. Vol. 14(2). 44-58.

Lurdic, S. and V. Mignon. (2008). Oil Prices and Economic Activity: An Asymetric Cointegration Approach. Energy Economics. Vol. 30(3). 847-855.

Monfared, Senam Shojaeipour and Fetullah Akin. (2017). The Relationship Between Exchange Rates and Inflation: The Case Iran. European Journal of Sustainavle Development. Vol. (4). 329-340.

Nurhasanah, Ade Irma., Soeharjoto Soekapdjo. (2019). DETERMINASI VOLATILITAS KURS RUPIAH TERHADAP DOLAR AMERIKA. Jurnal Akuntansi, Ekonomi dan Manajemen Bisnis. Vol. 7(1). 1-8.

Nuryati, Yati., Hermanto Siregar, Anny Ratnawati. (2006). DAMPAK KEBIJAKAN INFLATION TARGETING TERHADAP BEBERAPA VARIABEL MAKROEKONOMI DI INDONESIA. Buletin Ekonomi Moneter dan Perbankan. Vol. 9(1). 113-134.

Ofori, Collins Frimpong., Benjamin Adjei Danquah, Xuegong Zhang. (2017). The Impact of Money Supply on Inflation, A Case of Ghana. Imperial Journal of Interdisciplinary Reseach. Vol. 3(1). 2312-2319.

Soekapdjo, Soeharjoto., Debbie Aryani Tribudhi, Lucky Nugroho. (2019). Pengaruh Fundamental Ekonomi dan Kinerja Keuangan Terhadap Kredit Bermasalah Pada Bank Syariah Di Indonesia. Ekonika. Vol. 4 (2). 16-29.

Tribudhi, Debbie Aryani., Soeharjoto Sokapdjo. (2019). Determinasi transaksi dengan menggunakan uang elektronik di Indonesia. KINERJA. Vol 16(1). 78-84.

www.bi.go.id

www.investing.com

WWw.imf.org

www.worldbank.org 